\title{
The Multifaceted Development of Writing
}

\author{
Liliana Tolchinsky and Harriet Jisa
}

Becoming literate is part of an individual's linguistic development, and learning to write is an essential component of literacy. Children who have difficulties in acquiring writing are at risk in their linguistic and educational development. In this chapter, we review crucial landmarks in children's acquisition of writing in alphabetic systems, providing a developmental framework within which to characterize writing disabilities/difficulties, which may range from tracing a letter-shape to producing a coherent text. This diversity of areas of ability reflect the multiple meanings of writing, which can refer to the set of graphic signs used to represent an utterance, the method used for producing such signs (mode of production), or the linguistic features that characterize the resulting output. Each of these meanings corresponds to a domain of knowledge that children need to master in order to become competent writers: the forms and function of the signs of writing, the modality of production, and the written products. In the following, we discuss these and our developmental perspective on the evolving knowledge in each of these domains.

\section{The Meanings of Writing}

\section{The Graphic Signs}

Expressions such as writing systems illustrate the first sense of what we mean by "writing": symbol systems formed by a finite set of visible and enduring graphic elements that represent an utterance that can be understood without the intervention of the utterer (Daniels \& Bright, 1996). Alphabetic, syllabic, or logographic systems are broad categories of writing systems; all represent language in an arbitrary and conventional way (i.e., without an iconic or direct resemblance between the graphic elements and the objects or events they refer to) (Sampson, 1985). Writing systems are realized in language-specific orthographies (e.g., English, French, or Spanish, all use the same set of graphic marks, letters, but obey different rules of pairing letters to sounds for representing utterances). Learners of writing must acquire not only the alphabetic principle - that individual signs represent categories of sound - they must also gain language-specific orthographic knowledge.

(C) KONINKLIJKE BRILL NV, LEIDEN, 2018 | DOI: 10.1163/9789004346369_005

This is an open access chapter distributed under the terms of the prevailing CC-BY-NC License at the time of publication. 
Some languages have a transparent orthographic system (have a regular sound-letter correspondence), while others have a more opaque (less regular) relation between phonemes and graphemes. Languages differ in their transparency/opacity (the way that phonemes and graphemes map to each other). Studies have shown that children learn to read and spell earlier in more transparent orthographies (e.g., Babayigit, 20og; Goswami, Gombert, \& De Barrera, 1998; Kotoulas, 2004; Seymour, Aro, \& Erskine, 2003).

\section{The Mode of Production}

Expressions such as say it in writing refer to the biomechanical mode of production (i.e., non-speech, non-signing) used for encoding utterances. Unlike speaking or signing that can only be produced by voice or manual gestures, many different tools can be used for writing: pens, pencils, brushes, keyboards and fingers. All leave visible, more or less permanent marks that can be scrutinized offline by the same producer/writer or any other reader. Writers must learn to handle the instruments skillfully so that they can focus on their intended message, and they must learn to take advantage of writing which, in contrast to speaking, allows them to plan, revise, and edit the message.

\section{The Linguistic Features}

Finally, writing may refer to a discourse mode, the written language register. The possible and probable planning, revision, and editing, plus the dissociation between the producer and the product, lead to the deployment of linguistic resources which insure interpretation in the absence of online feedback: lexical precision, reformulations, explicit references, and explicit linkage between utterances, that are not compulsory in the presence of interlocutors but are essential in their absence. In addition to specific features of language, writing as a discourse mode involves identifying the communicative situation, including text type, communicative purpose, and audience needs.

The several meanings of writing are used interchangeably in the literature. Our motivation for distinguishing among them is to show that the process of learning to write is truly multifaceted. It includes acquiring a system of signs/symbols, language-specific rules of use of these (orthographic knowledge), realizing the peculiarities of this mode of production (awareness of the writing process), and gaining a full command of the linguistic resources expected in the written products (lexical, morpho-syntactic, and discursive knowledge). In addition, the several meanings of writing may serve to typify different kinds of writing disabilities. In order to characterize and treat writing disorders, it is important to determine what aspect of writing is involved. 


\section{A Developmental Perspective on Writing}

Learning to write is generally conceived of as highly dependent on formal teaching. Popular wisdom and linguistic textbooks usually contrast the natural acquisition of spoken language with the learning of written language (reading and writing), which requires specific instruction.

An alternative developmental view explores children's evolving knowledge prior to formal instruction, seeking to demonstrate that young children construct original and very precocious ideas about the practices of reading and writing. We view this perspective as useful for approaching writing disorders for two reasons: (1) it provides information crucial for distinguishing between those deviances that are part of writing development and those that are truly pathological, and (2) it provides invaluable details about pre-conventional writing behaviors. Most models of spelling (e.g., Ehri, 1982) refer to the period of initial development of writing (when children are not yet using conventional letters or even realizing that writing denotes spoken utterances) as prealphabetic. These models do not detail the specifics of the pre-alphabetic stage, as though the real thing starts only after children start looking for letterto-sound correspondences. Nevertheless, the pre-alphabetic period might be more protracted in delayed development — and many disorders manifest initially as delayed development. Looking at this period through a developmental lens can enable detection of significant early differences.

The developmental approach to writing originated during the late thirties with the work of Vygotsky (1978) and Luria (1929), whose aim was to explore "the pre-history of written language". This approach, revived almost sixty years later by the groundbreaking work of Ferreiro tracing the psychogenesis of writing, was followed by a remarkable number of studies in different languages, orthographies, and cultural contexts (e.g., Ferreiro \& Teberosky, 1979, in Spanish; Tolchinsky Landsmann \& Levin, 1987, in Hebrew; Chan \& Nunes, 1999, in Chinese). The basic idea is that, even when children have to incorporate knowledge of a conventional kind, they must make that knowledge their own and re-construct it in their own terms.

Another strand of thought is invented spelling, initiated by Read (1971). Based on his observations of pre-reading children who began writing, he viewed spelling as a linguistic process in which children attempt to map the sound structure of words. Read was also among the first to discover the important role of letter names in identifying phonemes and the importance of a child's own name in this discovery.

Finally, a parallel but more ethnographic, socio-cultural developmental perspective-emergent literacy-comes from the work of Clay (1982), McLane 
and McNamee (1990), Teale and Sulzby (1986), and others, who argue that children's interest in the written word is triggered and enhanced by writing practices at home and at school. They stress the fundamental importance of family literacy practices for success at school (Heath, 1983).

Becoming a proficient writer may require formal instruction and many years of guided practice. Nevertheless, there is strong evidence suggesting that children acquire information about the features of written language through participation in writing practices and informal interactions with parents and other adults (Auerbach, 1989; Robins \& Treiman, 2010; Weinberger, 1996). Moreover, there is increasing evidence that this informal information paves the way to further learning (Tolchinsky, Liberman, \& Alonso-Cortés, 2015). In the next section, we present empirical evidence that knowledge about the three meanings of writing evolves from early childhood through adolescence.

\section{Developing Knowledge of the Signs of Writing}

The child is sensitive to the different verbal behaviors that literate adults perform with printed messages - naming, asking questions, describing, and speaking in a certain cadence. Affordances of printed materials lead to differentiating writing from drawing and to an increasing awareness of the relationship between written symbols and oral language (Graham \& Winetraub, 1996; Traweek \& Berninger, 1997). Informal and structured observations have revealed that 2-year-olds produce different kinds of markings for the two requests to draw and to write (Sulzby, 1985).

Very early, children from different languages and cultures display an understanding of the general surface characteristics of print in their own attempts at writing. Children first learn about the formal features common to all writing systems - linearity, presence of units, lack of iconicity — and only later learn about features that are specific to the particular orthography to which they are exposed, such as directionality. In a study with over 300 English-speaking children ages 3 to 5 years, Puranik and Lonigan (2011) showed that all 3 -year-olds in the sample had acquired most of the universal writing features, while languagespecific features could only be found in the writing samples of 4- and 5-year olds. Different writing tasks have been used to test the influence of task type in determining the conventionality of writing forms used by preschoolers. Results show that from a very early age, children use the more advanced writing forms (e.g., letter or letter-like symbols) for their own name, but use wavy scribble or long strings of letter-like symbols (Schickedanz \& Casbergue, 2004; Vukelich \& Christie, 2009) for other words. These studies confirm the salience of the global 
visual pattern of writing, somehow extracted by the child from environmental print rather than resulting from a direct instructional strategy.

From this global pattern children will move to a focus on two levels of element, individual graphic signs and basic compounds. Two pieces of social information will help children in this task: learning to write their own names, and learning the names and sounds of letters. In literate communities, both parents and teachers tend to teach children how to write their own names before any other word; names constitute the first clearly meaningful text, resistant to being forgotten and stable in pronunciation. If a 3- or 4-year-old is told that a set of letters is his or her name, the child will remember it when presented with the same set at a later date, whereas for any other word this is not usually the case (Tolchinsky, 1992). After a pioneer study by Hildreth in the thirties (Hildreth, 1936), dozens of studies on early writing development have illustrated the crucial role of own-name writing in writing development (e.g., Bloodgood, 1999; Ferreiro \& Teberosky, 1979; Tolchinsky, Landsmann, \& Levin, 1987).

Also letters, their names and the sounds they stand for are meaningful pieces of knowledge children obtain from their environment. Children may at times acquire the letters from other words they have learned, but most frequently the child's name is the source and point of identification for the letters. As we shall see later, letter knowledge has been found to be a powerful preschool predictor of learning to spell across different spelling and educational systems (e.g., Cardoso-Martins, 1995; Levin \& Ehri, 20o9; Lonigan, Burgess, \& Anthony, 200o; Tolchinsky, Levin, Aram, \& McBride, 2011).

Parallel to learning the graphic elements of writing, children must discover the representational meaning of writing. Young toddlers, before age three, emit voices mimicking reading while gazing at a story book, showing their grasp of a link between verbal behavior and written objects.

In Luria's (1929/1978) pioneering study, he made the crucial observation that children began to introduce graphic differences into their writing, as some "scrawls" took on a longer or more rounded appearance mainly when the sentences referred to objects that differed in size. More recent research has shown that when recognizing words, children prefer more letters (longer words) to represent large objects (Lundberg \& Tornéus, 1978), and that this preference also appears in their own attempts at writing. For example, Hebrewspeaking children use more symbols, or space their symbols farther apart, when writing snake because snakes are longer than butterflies (Levin \& Tolchinsky Landsmann, 1990).

Luria (1929/1978) and Vygotsky (1978) both argued that from the moment children resort to referential devices, the natural development of writing has 
become one of cultural development, because a symbolic relation has been established: children have grasped the fundamental relationship that something stands for something else (Luria, 1929/1978; Scinto, 1986). Yet, the idea that writing represents referential differences can be applied only in certain circumstances, when there is some kind of contrast between the words, such as words that contrast in size (e.g., ant vs. elephant) or color (e.g., tomato vs. cucumber). Children must realize that writing relates to the sounds of words in order to develop a general model suitable for every writing task, because every word and sentence has a phonic aspect.

\section{Linking the Signs of Writing to Language}

How do children come to understand that written marks represent the sounds of words rather than their content or meaning? Alternative and probably complementary explanations have been offered to this phonetization process. According to one account, the process of interpretation of one's own writing triggers phonetization in an individual's writing (Tolchinsky, 2003). A second account posits that adults provide the necessary cues to guide children in linking writing to language (Robins \& Treiman, 2010), while a third attributes the development towards phonetization to children's increasing orthographic or orthotactic sensitivity.

\section{Interpreting One's Own Writing Triggers Phonetization}

Research has shown that whenever children are writing, either spontaneously or at the request of an adult (parent or interviewer), they can answer the question What did you put here? and interpret the graphic shapes they have produced. In experimental settings, they may reiterate verbatim the words the experimenter asked them to write (Tolchinsky Landsmann \& Levin, 1985, 1987), but in contextualized tasks or real life situations, they may resort to other sources of information. If a text appears under a picture, they may use what they see in the picture to interpret the text, similar to children's early reading where they often take meaning cues from objects near the print. Thus, in studies where a puppet moves a card with a printed word nearer to one object (seemingly accidentally), 3-year-old children often change their reports of what the word says to reflect the object closest to the card (Bialystok, 2000; Bialystok \& Martin, 2003). This mapping between a child's verbal interpretation of his/her own writing, irrespective of the source of information used, pushes them toward phonetization. 


\section{Adults as Guides Towards Phonetization}

In a recent study, Robins and Treiman (2010) proposed that parent speech about writing helps move young children toward phonetization. They analyzed all of the transcripts that involved parent-child conversations in English (MacWhinney, 2000), with children between 18 months and 5 years of age, and found that parents do speak to even very young children about writing, and that they speak about speech and writing in quite similar ways: using the word say to refer to both speech and writing (e.g., What didyou say? or What does that sign say?); using name and word interchangeably to refer to units of the written or spoken language (e.g., I just wrote my name, and what's the name of that thing?) (Robins \& Treiman, 2010). The authors suggest that this use of similar terms for speech and writing may help children to realize that the two systems symbolize the same thing, language.

\section{Orthographic or Phonotactic Sensitivity Helps Phonetization}

A third explanation comes from increasing evidence of an implicit orthographic knowledge that may facilitate children's establishment of phonological links between written and spoken elements. In traditional models of spelling, the period of being unaware of the links between writing and speaking is referred to as pre-alphabetic (Ehri, 2005; Ehri \& McCormick, 1998); children may recognize some sight words (thus Frith [1985] refers to this period of development as logographic) but no particular regularities are described. Children next move to partial correspondences between letter and sounds, then to exhaustive sound-letter correspondences. During these latter two stages, children's spelling decisions are basically phonographic, guided by phonological correspondences. Only during a fourth stage will children progress to an orthographic stage, which entails the ability to identify orthographic units without phonological analysis. Frith (1985) asserted that orthographic skills are mastered first for reading and later transferred to spelling. Others however have found that preliterate children develop crucial orthographic knowledge even before they are able to establish phonological links. Siegel and colleagues define orthographic knowledge as "both knowledge of the actual spelling of particular words and higher level conceptual skills, such as the recognition of the properties of words and sequences and typical positions of letters in English" (Siegel, Share, \& Geva, 1995, p. 262). Kaefer (2009) observed prereading 3-year-olds; they found that although 3-year-old children did not significantly distinguish numbers from letters, they did look significantly longer at a number or symbol than at letters in the same position of a pseudo-word. This suggests early implicit orthographic knowledge in 3-year-olds. In addition, 5year-olds identified letter strings as "words" although any combinations includ- 
ing non-letters or repeated letters were identified as non-words. These findings are in line with previous studies showing that before looking for phonological links between letters and sounds, children have certain criteria about the distinctive features graphic displays must fulfill in order to be readable. The mere presence of letters is not enough for something to be readable; if there are very few letters, it is unreadable, and similarly if the same letter is repeated many times, it is also unreadable (Ferreiro, 1982). These criteria are manifest especially in sorting and writing tasks and seem to hold true across languages and scripts (e.g., Tolchinsky \& Teberosky, 1998, for Spanish and Hebrew).

How are sound units mapped onto parts of the written string? Various studies suggest that syllables rather than phonemes are the first units of mapping letters to sound; the number of letters (or letter-like symbols) children use in writing words corresponds roughly to the number of syllables in the word they are attempting to write. Although evidence for the syllabic hypothesis is provided by case studies and in-depth longitudinal studies in Spanish (Tolchinsky, 2003), it is called into question mainly by studies carried out in English (e.g., Treiman, Tincoff, \& Richmond-Welty, 1996), which suggest that children use alternative methods to understand the relation between written and spoken words. Treiman and colleagues (1996) suggested, in line with Ehri (1993), that children begin to create links between printed words and spoken words "by finding links between letters in printed words and the names of the letters in the spoken words" (Treiman et al., 1996, p. 512). Five year olds found it easier to say the initial letter of a word if it was the name of an English letter rather than its corresponding sound (e.g., beach vs. bone because the spoken form of beach starts with /bi/, the name of the letter $\underline{b}$ ). Similar findings were reported for final letters, although letters at the end of words were more difficult to identify. In addition, children writing monosyllabic and disyllabic words in which the name of the letter coincided with part of the syllable showed no differences in the ease with which the initial letter of the bi-syllabic word or the first letter of the monosyllabic word were identified (bead vs. beaver), suggesting that children are not mapping at a syllable level but rather are using their knowledge of letter names. Success at spelling will vary according to the position of the letters (initial or final) in the word to be identified and whether or not the letter name fits the syllable or part of the word children are asked to spell.

In sum, children's discovery of links between letters and sound is a turning point in the conceptualization of writing. It means discovering a stable principle useful for representing any word. The first unit of letter-sound correspondence in certain languages is the syllable. The syllabic hypothesis seems to be language specific, emerging in certain languages but not in others, such as English. 
It might be the case, however, that during this period of writing development, children do not have a fixed, stable unit of correspondence: depending on the structures of words, children may vary the unit of correspondence between letters and sounds. This instability would characterize children's letter-to-sound mapping until the alphabetic principle is established, the principle by which "usable knowledge of the fact that phonemes can be represented by letters, such that whenever a particular phoneme occurs in a word, and in whatever position, it can be represented by the same letter" (Bryne \& FieldingBarnsley, 1989, p. 313).

Although some children, even before being formally taught, discover the alphabetic principle, as a rule the transition to alphabetic writing is gradual. In this transition to alphabetic writing, the specific phonological and morphological structures of a language, and the way in which these characteristics are reflected in the script, play a crucial role.

\section{Developing Knowledge of Writing as a Modality of Production}

Very early, before age 3, children realize that writing means leaving visible marks that can be looked at. Later they become aware that those marks are linked to spoken utterances. Although closely related, the production of spoken and written language differs crucially. In principle, the writer has more time for deciding what to say, more time for producing what is said, and the possibility of going back to the written output for revising and editing. The main distinctions between producing language in the spoken versus the written modality have been reflected in the models of the process of production. Beginning with the classical model of Hayes and Flower (1980), every proposal has included three basic processes: planning, translation, and revision, and most of these processes occur in parallel and recursively, rather than linearly and successively. To what extent is children's early awareness of the specific characteristics of writing reflected in their managing of the process of production accurately depicted in these models? A crucial way of studying the cognitive processes at work during text composition is by studying the temporal characteristics of language production.

In adults, the dynamics of text composition have been studied using a variety of methods, including think-aloud and reaction time tasks used to gauge the cognitive cost of the writing activity. There are far fewer studies of how children manage time during composition or how time allocation varies with development and level of expertise (Fayol, Foulin, Maggio, \& Lété, 2012). A common supposition is that children are so occupied with the mechanics of 
writing and orthographic decisions that they have much less time to devote to planning and revising (Chanquoy 2001). Fayol and his associates (Fayol \& Monchon, 1997; Fayol \& Monteil, 1988), using a narrative completion production task (in French) with predictable vs. unpredictable endings, found 5 th graders and adults had shorter clause-initial and medial pauses and faster writing rates than 3 rd graders, whose attention was most likely devoted to transcription, leaving fewer cognitive resources available for managing higher dimensions. In an additional study, they found that consistent spelling also contributed to shorter pauses and faster rate, confirming earlier results obtained by Chanquoy and colleagues (Chanquoy, Foulin, \& Fayol, 1991) that, beyond the predictable effect of content and syntactic complexity, orthography made a small but significant contribution to pause length. Fayol and Stephant (1991) also evaluated the specific weight of high-level dimensions on pause length and writing speed, and found that overall pause duration and transcription time were significantly longer for children than for adults, and the distribution of their pauses differed. They concluded that, while adults made use of subsequent pause durations and varying writing speed to manage other dimensions of the writing task, children began transcribing immediately and had to process all dimensions during production. One key difference between adults and children relates to the emergence of an initial pre-writing pause: adults strategically devote time to planning content and syntax before beginning to write, while younger writers start without devoting time to planning.

An interesting recent line of developmental work focuses on writing bursts (Alves, Branco, Castro, \& Olive, 2012). Writers build up texts in a piecemeal fashion, with bursts of writing activity interspersed by production pauses (Chenoweth \& Hayes, 2001, 2003); as they develop, children produce longer bursts. Alves and colleagues (Alves et al., 2012), studying Portuguese-speaking 9-year-old children with varying levels of transcription skills, found that faster transcription speed leads to longer language bursts and overall better text quality. On-line measures of writing efficiency are crucial for identifying individual differences in children's writing efficiency and for identifying those who struggle with writing fluency. The study of the dynamics of online text composing, comparing typical with atypical developing writers, may shed light on the extent to which individual differences are related to (1) the application of different writing strategies, (2) the different weight of transcription factors (handwriting and spelling), (3) linguistic factors related to syntax and vocabulary, or (3) higher level factors such as content or knowledge of task schemas. 


\section{Developing Knowledge about Written Language}

Research on the development of awareness about writing as discourse has progressed along two distinct but parallel lines. The first concerns the development of the formal linguistic features of writing - learning to form letters, spell words, construct sentences, and use the written, more formal, language register. The second is concerned with the development of task schemas (Hayes \& Flower, 1980) or knowledge of specific genre constraints. Largely corresponding to these two areas of development are two complementary bodies of research. The first supposes that children's knowledge of written language develops from low levels, such as handwriting or word spelling, and then proceeds to higher levels, such as overall text construction. This line of research argues that it is only after having gained control of handwriting and word spelling that children can develop knowledge about written discourse. A second line of research investigates what children know about written discourse well before they have mastered the signs of writing (Blanche-Benveniste, 1982).

The first line of research developed, in large part, in reaction to the model of writing proposed by Hayes and Flowers (1980), which involved three major components: the task environment (topic, audience, and writer's motivation), the writer's long-term memory (knowledge of the topic, language, and genre), and the writing process (planning, transcribing, and revision). This influential model was developed to capture the problem-solving nature of writing for adult writers. For researchers studying the development of writing, however, the role played by the transcribing component seemed to require further elaboration (Fayol, 2012), because handwriting and spelling can present major stumbling blocks to novice writers (Bereiter \& Scardamalia, 1987; Graham, 1990). McCutchen (2012) introduced the capacity theory of writing which holds that, given limited cognitive resources, any variation in the processing cost of a given component will impact the use of other components, with either low level components (handwriting or spelling) affecting high level processes (planning content, creating a text) or vice versa. Lack of automaticity of transcription skills can severely interfere with the writing process, constraining content generation and fluency.

\section{Text Knowledge and Familiarity with Writing Task-Schemas}

In the second line of research, written language is conceived of first and foremost as a discourse mode. Written language development is seen as the acquisition of a repertoire of discourse modes that are socio-culturally bounded 
(Berman \& Nir-Sagiv, 2007; Dyson, 1983). The bulk of research from this perspective studies texts produced in different discourse modes, rather than only writing letters or words, and seeks to understand what children know about texts before gaining full command of spelling (Pontecorvo \& Zucchermaglio, 1988; Sandbank, 2001). It has been observed, for example, that when 4- to $5^{-}$ year-olds who do not yet know how to spell are asked to dictate stories that are meant to be written, they use linguistic forms typical of writing (BlancheBenveniste, 1982).

By separating the transcriptional from the discursive aspects of written language, Pontecorvo and Zucchermaglio (1989) showed that before mastering the alphabetic code, children are aware of many linguistic features of written language. At the same time, full developments of the various aspects of oral language, such as complex grammar, definitional vocabulary, and listening comprehension, shown to have substantial predictive relations with later conventional literacy skills (Lonigan \& Shanahan, 2009), are enhanced by children's experience with written language. In this sense written language functions as a device for developing knowledge (Galbraith, 2009), not just for translating existing knowledge from the spoken modality.

Support for this line of thought is provided by findings that very young children show no confusion between genres (e.g., they do not tell a story if asked to describe a house). Preschoolers distinguish between the modes of discourse to be expected from different printed materials (e.g., 4- to 5-yearolds hearing a food recipe from a storybook or a typical fairy tale from a newspaper react with surprise); they are able to produce different graphic layouts for writing shopping lists, newspaper news, advertisements, and poetry (Pontecorvo \& Zucchermaglio, 1989), before attaining full command of the phonographic conventions of the written system.

These facts are an indication that preschoolers differentiate among genres. It is obvious, however, that children must also learn to produce cohesive and semantically rich texts for each of these purposes. Evidence shows that this ability is attained in some genres before others. Bereiter and Scardamalia (1987) propose that young writers use a knowledge-telling strategy in which content is retrieved in memory and written down as it comes to mind. More expert writers use a knowledge-transforming strategy by elaborating the communicative problem to be solved and setting goals built upon this elaboration to guide the generation and the evaluation of content. This difference in writing strategy helps us understand why narrative texts, which depend largely on temporal and causal relations, are among the first text types to be mastered by children, both in the spoken and written modalities (Berman, 1988, 1995; Fayol, 2012; Jisa, 2000). Children can retrieve the isolated events from memory and write them 
down in the order that they occurred. The global structure of narrative texts is familiar to young children: they know that stories have a beginning, chronologically ordered events, and an ending. Thus, the cognitive cost of retrieving the narrative script in long-term memory is lower than for other text types. Argumentative or expository texts depend crucially on the elaboration of communicative goals and the planning of ideas (Boscolo, 1990; Britton, 1994; Ravid \& Berman, 2010). The global structure of an expository text is less familiar to children and, thus, the cognitive costs are higher than those associated with narrative. Thus, while a knowledge-telling strategy is sufficient for writing a minimal narrative text, a knowledge-transforming strategy is required for writing an expository text.

Vocabulary choices are also intricately related to text genre (Biber, 1988; Olinghouse \& Wilson, 2013). In comparisons of narrative and expository texts, Berman and Verhoeven (2002) observed that the adults' and children's expository texts had longer and more Latinate words than the narrative texts, even for the youngest writers (9-year-olds), and Gardner (2004) found that 5 th graders' narrative texts contained more frequent words while their expository texts had higher lexical diversity.

Beers \& Nagy (2011) compared narrative, descriptive, compare/contrast, and persuasive texts written by children and adolescents. They found both strong developmental differences and genre differences. Persuasive texts had longer clauses than the descriptive, compare/contrast, and narrative texts. In comparisons of narrative and expository texts, the expository texts showed more nominalizations (Ravid, van Hell, Rosado, \& Zamora, 2002), infinitives, participles, and gerunds (Berman \& Nir-Sagiv, 2007), clause-lengthening constructions that are not common before high school age (Berman, 2009). With development, writers create more adequate mental representations of the discourse genres and of the linguistic constructions which characterize them (Berman \& Nir-Sagiv, 2007).

Syntactic density has long been used as a yardstick for measuring clause connectivity in children's written discourse. The number of clauses per sentence, or the terminal unit (t-unit), increases gradually from elementary to high school (Hunt, 1970; Crowhurst \& Piche, 1979; Scott \& Windsor, 2000). Over the course of schooling, new grammatical constructions gradually come into use in children's written texts, such as nominalizations (the destruction of the city), adverbial complements (because, while, when), relative clauses (the mountain that we visited) and discourse connectors (nevertheless, however).

Both the lexicon and syntax contribute to tighter packaging in written discourse. Becoming a proficient writer involves gaining mastery over more compact means of establishing the flow of information, resulting in texts that show 
more densely integrated packages of information. Once children are over the major hurdles of letter formation and spelling, it has been argued that writing may actually facilitate the use of less frequent and more complex grammatical constructions.

\section{Form and Function: From Emergence to Divergence in Usage}

During the process of "growing into academic language", children encounter texts that contrast in genre. While exploring new text genres, children not only encounter new grammatical constructions, they also acquire new functions for the grammatical constructions that they already use (Jisa, 2004). Learning to produce contrasting text types is invaluable for children to capture the relationship between form and function of a given construction.

Berman (1987) introduced a useful distinction between a native language user and a proficient language user, which captures how children's language is impacted by becoming literate. Native language users produce fully grammatical structures in everyday conversation, and this use characterizes children's early language. Exposure to and use of written language in knowledge-based school activities challenges the children to expand vocabulary, syntactic repertoire, form-function mappings, and more importantly, to use language which is appropriate in register. Adults know how to fine tune language to fit the situation (e.g., when using medical practitioner or physician is more appropriate than doctor). Important aspects of register variation are revealed to children through their school-situated literacy activities.

\section{Conclusion}

Our goal in this chapter was to offer a developmental framework to guide the characterization and timing of writing difficulties. We have attempted to illustrate how learning to write involves development at many levels, ranging from low-level aspects (handwriting and spelling) to higher levels (syntax and semantics) marshalled during planning of different types of texts. Understanding how these different levels emerge and develop is crucial to informing clinical practices directed to children with motor or language difficulties. Struggling with writing is a barrier to educational progress (Connelly, Dockrell, \& Barnett, 2012). Understanding exactly where the child is struggling is critical for designing remediation. 


\section{References}

Alves, R.A., Branco, M., Castro, S.L., \& Olive, T.(2012). Effects of handwriting skill, output modes, and gender on fourth graders-pauses, language bursts, fluency and quality. In V.W. Berninger (Ed.), Past, present and future contribution of cognitive writing research to cognitive psychology (pp. 389-402). New York: Psychology Press.

Babayigit, S. (2009). Reading and spelling development in transparent alphabetic orthographies: Points of convergence and divergence. In C. Wood \& V. Connelly (Eds.), Contemporary perspectives on reading and spelling (pp. 133-148). London: Routledge.

Beers, S., \& Nagy, W. (2011). Writing development in four genres from grades three to seven: Syntactic complexity and genre differentiation. Reading and Writing: An Interdisciplinary Journal, 24, 183-202.

Berman, R.A. (1988). On the ability to relate events in narratives. Discourse Processes, 28, 261-285.

Berman, R.A. (1995). Narrative competence and storytelling performance: How children tell stories in different contexts. Journal of Narrative and Life History, 5, 285-313.

Berman, R., \& Verhoeven, L. (2002). Developing text-production abilities across languages, genre and modality. Written Language and Literacy, 5, 1-22.

Berman, R., \& Nir-Sagiv, B. (2007). Comparing narrative and expository text construction across adolescence: A developmental paradox. Discourse Processes, 43, 79-120.

Bialystok, E., \& Martin, M.M. (2003). Notation to symbol: Development in children's understanding of print. Journal of Experimental Child Psychology, 86, 223-243.

Bialystok, E. (2000). Symbolic representation across domains in preschool children. Journal of Experimental Child Psychology, 76, 173-189.

Biber, D. (1988). Variation across speech and writing. Cambridge: Cambridge University Press.

Blanche-Benveniste, C. (1982). La escritura del lenguaje dominguero. In E. Ferreiro \& M. Gómez Palacio (Eds.), Nuevas perspectivas sobre los procesos de lectura y escritura (pp. 247-270). Mexico DF: Siglo XXI.

Bloodgood, J. (1999). What's in a name? Children's name writing and literacy acquisition. Reading Research Quarterly, 34, 342-367.

Boscolo, P. (1990). The construction of expository text. First Language, 10, 217-230.

Britton, B.K. (1994). Understanding expository text. In M.A. Gernsbacher (Ed.), Handbook of psycholinguistics (pp. 641-674). San Diego: Academic Press.

Byrne, B., \& Fielding-Barnsley, R. (1989). Phonemic awareness and letter knowledge in the child's acquisitions of the alphabetic principle. Journal of Educational Psychology, 8 o (1), 313-321.

Cardoso-Martins, C. (1995). Sensitivity to rhymes, syllables and phonemes in literary acquisition in Portuguese. Reading Research Quarterly, 30, 808-828. 
Chan, L., \& Nunes, T. (1998). Children's understanding of formal and functional constraints in written Chinese. Applied Psycholinguistics, 19, 115-131.

Chanquoy, L., Foulin, J.N., \& Fayol, M. (1991). The on-line management of short text writing by children and adults. European Bulletin of Cognitive Psychology, 10, 513540 .

Chanquoy, L. (2001). How to make a revising task easier? A study of text revision from $3^{\text {rd to }} 5^{\text {th }}$ grade. British Journal of Educational Psychology, 71, 15-41.

Chenoweth, A., \& Hayes, J. (2001) Fluency in writing: Generating text in L1 and L2. Written Communication, $18,80-98$.

Chenoweth, A., \& Hayes, J. (2003). The inner voice in writing. Written Communication, 20, 99-118.

Clay, M. (1982). What did I write? Beginning writing behaviour. Portsmouth, N H: Heinemann Educational Books.

Connelly, V., Dockrell, J., Walter, K., \& Critten, S. (2012). Predicting the quality of composition and written language bursts from oral language, spelling, and handwriting skills in children with and without specific language impairment. Written Communication, 29, 278-302

Crowhurst, M., \& Piche, G.L. (1979). Audience and mode of discourse effects on syntactic complexity in writing at two grade levels. Research in the Teaching of English, 13, 101-109.

Daniels, P.T., \& Bright, W. (Eds.) 1996. The world's writing systems. New York: Oxford University Press.

Dyson, A.H. (1983). The role of oral language in early writing processes. Research in the Teaching of English, 17, 1-30.

Ehri, L. (1999). Phases of development in learning to read words. In J. Oakhill \& R. Beard (Eds.), Reading development and the teaching of reading: A psychological perspective (pp. 79-108). Oxford, uk: Blackwell Publishers.

Ehri, L.C., \& McCormick, S. (1998). Phases of word learning: Implications for instruction with delayed and disabled readers. In R.B. Ruddell \& N.J. Unrau (Eds.), Theoretical models and processes of reading (5th Ed.) (pp. 365-389). Newark, DE: International Reading Association, Inc.

Ehri, L.C. (1993). How English orthography influences phonological knowledge as children learn to read and spell. In R.J. Scales (Ed.), Literacy and language analysis (pp. 21-43). Hillsdale, NJ: Erlbaum.

Ehri, L.C. (2005). Learning to read words: Theory, finding and issues. Scientific Studies of Reading, 9, 167-188.

Fayol, M., \& Stephant, I. (1991). Assessing cognitive load in writing: An on-line method. Paper presented at SIG Writing EARLI, Paris, January 23-24.

Fayol, M. (2012). Cognitive processes of children and adults in translating thought into written language in real time. In V.W. Berninger (Ed.), Past, present and future 
contribution of cognitive writing research to cognitive psychology (pp. 27-59). New York: Psychology Press.

Fayol, M., Foulin, J-N., Maggio, S., \& Lété, B. (2012). Towards a dynamic approach of how children and adults manage text production. In E. Grigorenko, E. Mambrino, \& D. Preiss (Eds.), Writing: A mosaic of perspectives (pp. 141-158). New York: Psychology Press.

Ferreiro, E., \& Teberosky, A. (1979). Los sistemas de escritura en el desarollo del niño. Mexico: Siglo Xxxı Editores (1982). Literacy before schooling. New York: Academic Press.

Ferreiro, E. (1982). The relationship between oral and written language: The children's point of view. In A. Figurel (Ed.), Forging ahead in reading. Newark, DE: International Reading Association.

Frith, U. (1985). Beneath the surface of developmental dyslexia. In K. Patterson, M. Coltheart, \& J. Marshall, (Eds.), Surface dyslexia (301-330). London: Lawrence Erlbaum Associates.

Galbraith, D. (2009). Writing as discovery. Teaching and learning writing: psychological aspects of education-current trends. British Journal of Educational Psychology Monograph Series, II, 5-26.

Gardner, D. (2004). Vocabulary input through extensive reading: A comparison of words found in children's narrative and expository reading materials. Applied Linguistics, 25(1), 1-37.

Goswami, U., Gombert, J., \& De Barrera, F. (1998). Children's orthographic representations and linguistic transparency: Nonsense word reading in English, French and Spanish. Applied Psycholinguistics, 19, 19-52.

Graham, S., \& Winetraub, N. (1996). A review of handwriting research: Progress and prospects from 1980 to 1994. Educational Psychology Review, 8, 7-87.

Graham, S. (1990). The role of production factors in learning disabled students' compositions. Journal of Educational Psychology, 82, 781-791.

Hayes, J.R., \& Flower, L.S. (1980). Identifying the organization of writing processes. In L.W. Gregg \& E.R. Steinberg (Eds.), Cognitive processes in writing (pp. 31-50). Hillsdale, NJ: Erlbaum.

Heath, S.B. (1983/1996). Ways with Words: Language, life, and work in communities and classrooms. New York and Cambridge: Cambridge University Press.

Hildreth, G. (1936). Developmental sequences in name writing. Child Development, 7 , 291-303.

Hunt, K. (1970). Syntactic maturity in school children and adults. Monographs of the Society for Research in Child Development, 35, iii-67.

Jisa, H. (2000). Increasing cohesion in narratives: A developmental study of maintaining and reintroducing subjects in French. Linguistics 38, 591-62O.

Jisa, H. (2004). Growing into academic French. In R. Berman (Ed.), Later language devel- 
opment: Typological and psycholinguistic perspectives. TiLAR3 (Trends in Language Acquisition Research) (135-161). Amsterdam: John Benjamins.

Jisa, H. (2005). Developing alternatives for indicating discourse stance. In D. Ravid \& H. Shyldkort (Eds.), Perspectives on language and language development: Essays in honor of Ruth A. Berman (pp. 357-374). Dordrecht: Kluwer Academic Publishers.

Kaefer, T. (2009). Implicit, eclipsed, but functional: The development of orthographic knowledge in early readers. PhD Dissertation submitted in the Department of Psychology \& Neuroscience in the Graduate School of Duke University

Kotoulas, V. (2004). The development of phonological awareness throughout the school years: The case of a transparent orthography. Lt-Educational Studies in Language and Literature, 4, 183-201.

Levin, I., \& Ehri, L.C. (2009). Young children's ability to read and spell their own and classmates' names: The role of letter knowledge. Scientific Studies of Reading, 13, 125 .

Levin, I., \& Tolchinsky Landsmann, L. (1990). Becoming literate: Referential and phonetic strategies in early reading and writing. European Journal of Behavioural Development, 12, 369-384.

Lonigan, C.J., \& Shanahan, T. (2009). Executive summary: Developing early literacy. Report of the National Early Literacy Panel. Washington, DC: National Institute for Literacy.

Lonigan, C.J. Burgess, S.R., \& Anthony, J.L. (2000). Development of emergent literacy and early reading skills in preschool children: Evidence from a latent-variable longitudinal study. Developmental Psychology, 36, 596-613.

Lundberg, I., \& Tornéus, M. (1978). Nonreaders' awareness of the basic relationship between spoken and written words. Journal of Experimental Child Psychology, 25, 404-412.

Luria, A.R. (1929/1978). The development of writing in the child. In M. Cole (Ed.), The selected writings of A.R. Luria (146-194). New York: M.E. Sharpe.

MacWhinney, B. (2000). The CHILDE S Project: Tools for analyzing talk. Volume 1: Transcription format and programs. Volume 2: The database. Mahwah, NJ: Lawrence Erlbaum Associates.

McCutchen, D. (2012). Phonological, orthographic, and morphological word-level skills supporting multiple levels of the writing process. In V.W. Berninger (Ed.), Past, present and future contribution of cognitive writing research to cognitive psychology, (pp. 197-216). New York: Psychology Press.

McLane, J.B., \& McNamee, G.D. (1990). Early literacy. Cambridge: Harvard University Press.

Olinghouse, N.G., \& Wilson, J. (2013). The relationship between vocabulary and writing quality in three genres. Reading and Writing: An Interdisciplinary Journal, 26, 45-65. 
Pontecorvo, C., \& Zucchermaglio, C. (1988). Modes of differentiation in children's writing construction. European Journal of Psychology of Education, 3, 371-384.

Pontecorvo, C., \& Zucchermaglio, C. (1989) From oral to written text: How to analyze children dictating stories. Journal of Reading Behavior, 21(2), 109-125.

Puranik, C.S., \& Lonigan, C.J. (2011). From scribbles to scrabble: Preschool children's developing knowledge of written language. Reading and Writing: An Interdisciplinary Journal, 24, 567-589.

Ravid, D., \& Berman, R. (2010). Developing noun phrase complexity at school-age: A text-embedded cross-linguistic analysis. First Language, 3o, 3-26.

Ravid, D. (2002). A developmental perspective on root perception in Hebrew and Palestinian Arabic. In Y. Shimron (Ed.), The processing and acquisition of root-based morphology (pp. 293-319). Amsterdam: Benjamins.

Ravid, D., van Hell, J., Rosado, E., \& Zamora, A. (2002). Subject NP patterning in the development of text production:Speech and writing. Written Language and Literacy, $5,69-94$.

Read, C. (1971). Children's creative spelling. London: Routledge \& Kegan Paul.

Robins, S., \& Treiman, R. (2010). Learning about writing begins informally. In D. Aram \& O. Korat (Eds.), Literacy development and enhancement across orthographies and cultures, Literacy Studies 101 (pp. 17-29). Springer us.

Sampson, G. (1985). Writing systems. London: Hutchinson and Stanford, CA: Stanford University Press.

Sandbank, A. (2001). On the interplay of genre and writing conventions in early text writing. In L. Tolchinsky (Ed.), Developmental aspects in learning to write (pp. 5576). Dordrecht: Kluwer.

Scardamalia, M., \& Bereiter, C. (1987). Knowledge telling and knowledge transforming in written composition. Advances in Applied Psycholinguistics, 1, 142.

Schickedanz, J., \& Casbergue, R. (2004). Writing in preschool: Learning to orchestrate meaning and marks. Newark, DE. International Reading Association.

Scinto, L.F.M. (1986). Written language and psychological development. New York: Academic Press.

Scott, C., \& Windsor, J. (2000). General language performance measures in spoken and written narrative and expository discourse in school-age children with language disabilities. Journal of Speech, Language, and Hearing Research, 43, 324-339.

Seymour, P.H.K., Aro, M., \& Erskine, J.M. (2003). Foundation acquisition literacy in European orthographies. British Journal of Psychology, 94, 143-174.

Sulzby, E. (1985). Children's emergent reading of favorite storybooks: A developmental study. Reading Research Quarterly, 20, 458-481.

Teale, W., \& Sulzby, E. (Eds.) (1986). Emergent literacy: Writing and reading. Norwood, NJ: Ablex.

Tolchinsky, L. (1992). El aprendizaje del lenguaje escrito. Barcelona: Anthropos. 
Tolchinsky, L. (2003). The cradle of culture. Mahwah, N.J.: Lawrence Erlbaum.

Tolchinsky, L., \& Jisa, H. (20o9). Developing a depersonalised discourse stance in typologically different languages: Written expository texts. Written Language and Literacy, 12, 1-25.

Tolchinsky, L., \& Teberosky, A. (1998). The development of word segmentation and writing in two scripts. Cognitive Development, 13, 1-21.

Tolchinsky Landsmann, L., \& Levin, I. (1985). Writing in preschoolers: An age-related analysis. Applied Psycholinguistics, 6, 319-339.

Tolchinsky Landsmann, L., \& Levin, I. (1987). Writing in four- to six-year-olds: Representation of semantic and phonetic similarities and differences. Journal of Child Language, 14, 127-144.

Tolchinsky, L., Levin, I., Aram, D., \& McBride-Chang, C. (2011). Building literacy in alphabetic, abjad and morphosyllabic systems. Reading and Writing. An Interdisciplinary Journal, 25(7), 1573-1598. doi:10.1007/s11145-011-9334-7

Tolchinsky, L., Liberman, G., \& Alonso-Cortés, Ma D. (2015) Explaining first graders achievements in spelling and word separation in shallow orthographies. Journal of Writing Research, 6(3), 279-316.

Traweek, D., \& Berninger, V. (1997). Comparison of beginning literacy programs: Alternative paths to the same learning outcome. Learning Disability Quarterly, 20, 160168.

Treiman, R., Tincoff, R., \& Richmond-Welty, D. (1996). Letters' names help children to connect print and speech. Developmental Psychology, 32, 505-514.

Vukelich, C., \& Christie, J. (2009). Building a foundation for preschool literacy: Effective instruction for children's reading and writing development. Newark, DE. International Reading Association

Vygotsky, L.S. 1978. Mind in society. Cambridge, MA: Harvard University Press.

Weinberger, J. (1996). Literacy goes to school. London: Paul Chapman Publishing. 